\title{
Mini-open lateral retropleural/retroperitoneal approaches for thoracic and thoracolumbar junction anterior column pathologies
}

\author{
Peter A. Christiansen, MD, ${ }^{1,2}$ Shengbin Huang, MD, ,3 Justin S. Smith, MD, PhD, ${ }^{1}$ \\ Mark E. Shaffrey, MD, ${ }^{1}$ Juan S. Uribe, MD, ${ }^{5}$ and Chun-Po Yen, MD ${ }^{1}$ \\ 1Department of Neurological Surgery, University of Virginia Health System, Charlottesville, Virginia; ${ }^{2}$ Neurosurgery Department, \\ Southern California Permanente Medical Group, San Diego, California; ${ }^{3}$ Department of Orthopedics, Guigang City People's \\ Hospital, Guigang; ${ }^{4}$ Guangxi Medical University, Nanning, Guangxi, People's Republic of China; and ${ }^{5}$ Department of \\ Neurosurgery, Barrow Neurological Institute, Phoenix, Arizona
}

OBJECTIVE Advancements in less invasive lateral retropleural/retroperitoneal approaches aim to address the limitation of posterolateral approaches and avoid complications associated with anterior open thoracotomy or thoracoabdominal approaches.

METHODS Consecutive patients treated with a mini-open lateral approach for thoracic or thoracolumbar anterior column pathologies were analyzed in a retrospective case series including clinical and radiographic outcomes. Special attention is given to operative techniques and surgical nuances.

RESULTS Eleven patients underwent a mini-open lateral retropleural or combined retropleural/retroperitoneal approach for thoracic or thoracolumbar junction lesions. Surgical indications included chronic fracture/deformity $(n=5)$, acute fracture $(n=2)$, neoplasm $(n=2)$, and osteomyelitis $(n=2)$. The mean length of postoperative hospital stay was 7.2 days (range 2-19 days). All patients ultimately had successful decompression and reconstruction with a mean follow-up of 16.7 months (range 6-29 months). Axial back pain assessed by the visual analog scale improved from a mean score of 8.2 to 2.2. Complications included 1 patient with deep venous thrombosis and pulmonary embolism and 1 with pneumonia. One patient developed increased leg weakness, which subsequently improved. One patient undergoing corpectomy with only lateral plate fixation developed cage subsidence requiring posterior stabilization.

CONCLUSIONS Mini-open lateral retropleural and retroperitoneal corpectomies can safely achieve anterior column reconstruction and spinal deformity correction for various thoracic and thoracolumbar vertebral pathologies.

https://thejns.org/doi/abs/10.3171/2020.6.FOCUS20360

KEYWORDS corpectomy; lateral approach; retroperitoneal; retropleural

$\mathrm{P}$ OSTERIOR approaches are the primary workhorse for most spinal lesions; however, direct access to certain anterior column pathologies offers distinct advantages. Traditional transthoracic or thoracoabdominal approaches provide unobstructed surgical corridors to decompress the often ventrally located cord-compressing lesions and offer biomechanically stronger anterior column reconstruction. These procedures, however, involve extensive surgical exposure with high risks of pulmonary complications. ${ }^{1}$

Less invasive lateral retropleural or combined retropleural/retroperitoneal (extracoelomic) approaches can access anterior spinal column pathologies with reduced collateral damage compared to that associated with traditional approaches. ${ }^{2-4}$ To successfully perform the miniopen lateral retropleural or combined retropleural/retroperitoneal corpectomy, a sound knowledge of the relevant surgical anatomy and the surgical nuances is required. We detail the operative techniques in this study and present the clinical and imaging outcomes of a small case series.

\section{Methods \\ Patient Population}

Prospectively maintained data from consecutive patients undergoing lateral retropleural/retroperitoneal decompres- 
sion and reconstruction of anterior column pathologies involving the thoracic spine or thoracolumbar junction between January 2017 and December 2019 were analyzed. The patients were followed regularly for neurological outcome, complications, and back pain graded with the visual analog scale (VAS) pre- and postoperatively. Long-cassette radiographs or, if indicated, $\mathrm{CT} / \mathrm{MR}$ images were obtained to evaluate instrumentation, junctional failure, and global alignment. The Cobb angle, which was measured across the kyphotic deformity between the cranial and caudal endplates of the intact vertebral bodies above and below the targeted spine segment, was evaluated.

\section{Surgical Technique}

Patients underwent general anesthesia using singlelumen endotracheal tubes because lung deflection was not needed. Patients were secured to the operating table in a true radiographic lateral decubitus position with adhesive tape. Lesion laterality in general dictated the side of approach. For a midline lesion, the right lateral decubitus position (left-sided approach) was preferred to avoid the inferior vena cava and liver at the thoracolumbar and midthoracic to lower thoracic levels. The left lateral decubitus position (right-sided approach) was used for the upper thoracic spine. Neuromonitoring was conducted throughout the procedure.

The vertebral bodies of interest were localized with a C-arm fluoroscope. A 2- to 3-inch oblique incision was marked over the rib directly lateral to the targeted vertebral bodies and extended following the rib posteriorly and superiorly. The latissimus dorsi was divided and the periosteum was dissected off the rib circumferentially. The exposed rib was resected and saved for autograft. Extending rib resection more posterior facilitates perpendicular tubular retractor placement. The endothoracic fascia, a loose layer of connective tissue deep to rib and intercostal muscles, was incised to enter the retropleural space, thereby exposing the parietal pleura (Fig. 1A). The retropleural space was expanded with blunt and sharp dissection to separate the parietal pleura from the endothoracic fascia. Using a lung retractor to hold back the parietal pleura, further dissection was carried out craniocaudally, and then subsequently followed the curve of the thoracic wall dorsally and medially toward the targeted vertebra (Fig. 1B).

For thoracolumbar junction pathologies, lateral costal and posterior spinal diaphragmatic attachments need to be detached. Detaching the diaphragm from the 9th, 10th, 11th, and 12th ribs laterally allows access to detach the lateral arcuate ligament from the 12th rib's distal tip. This exposes the quadratus lumborum muscle, and the lateral arcuate ligament can be followed to its medial attachment on the L1 transverse process. Moving medially, the diaphragm attachment continues on as the medial arcuate ligament, spanning over the psoas muscle. Sharp dissection is needed to release the attachment to the L1 transverse process. Continuing blunt dissection medially will detach the diaphragm from the vertebral bodies up to the ipsilateral crus. Dissection of the crus exposes the anterolateral aspects of vertebral bodies. Mobilizing the psoas posteriorly will enhance exposure.
After exposure an expandable tubular retractor was placed, secured to a table-mounted arm, and opened to expose the targeted vertebral bodies and disc spaces. Periosteum was cleaned from the rib head of the targeted vertebral levels. The corresponding rib head of the corpectomy site was removed to expose the pedicle and the disc space. The rib head attaching to the vertebral body below the targeted level was at least partially removed to expose the disc space below the corpectomy site. The adjacent discs were incised with a knife, and a Cobb elevator was used to detach the cartilaginous endplates from vertebral bodies. An ultrasonic bone scalpel was used to create perpendicular cuts in the vertebral body of interest in front of the posterior wall and behind the anterior wall. High-speed drill and pituitary rongeurs completed the corpectomy and lesion resection by continuing toward the contralateral vertebral body wall. At the surgeon's discretion, the anterior wall can be either removed completely or thinned to a cortical shell to protect the visceral structures and great vessels.

Once the corpectomy trough was created, a high-speed drill was used to remove the ipsilateral pedicle, exposing the anterolateral aspect of the thecal sac. The bony fragments or tumor along with the posterior longitudinal ligament were dissected away from the thecal sac ventrally into the corpectomy defect by using curettes, and then were removed (Fig. 1C). The endplates were then prepared for arthrodesis. An expandable cage with wide rectangular end caps packed with morselized rib autograft was inserted into the intervertebral space under fluoroscopy to a tight fit, and then was expanded to correct any kyphosis (Fig. 1D).

After adequate hemostasis, the retractor was removed. A medium Hemovac drain was placed in the retropleural space and the incision was closed layer by layer. In cases with a breach of parietal pleura, a red rubber tube was placed into the pleural cavity and the other end was submerged in normal saline. A Valsalva maneuver was then performed to expel trapped air. If continuous air leakage from the red rubber tube occurred, a chest tube would be placed. Otherwise, the red rubber tube was removed before the last fascial stitch was tied down.

The fusion construct was stabilized with a lateral plate/ screws in 1 patient. Eight patients underwent posterior percutaneous pedicle screw fixation. Two patients underwent staged long-segment posterior open instrumentation for deformity correction.

\section{Results}

A total of 11 patients with disabling back pain and/ or neurological deficits underwent a retropleural or combined retropleural/retroperitoneal approach for thoracic or thoracolumbar junction lesions without assistance from an approach surgeon (Table 1). The mean follow-up was 16.7 months (range 6-29 months). There were 6 male and 5 female patients with a mean age of 57 years (range 17-79 years). The spinal pathologies treated were acute fracture in 2 patients (Fig. 2); neoplasm in 2 patients (1 with aggressive, benign hemangioma, and 1 with metastasis from breast cancer); osteomyelitis/discitis in 2 patients (Fig. 3); 


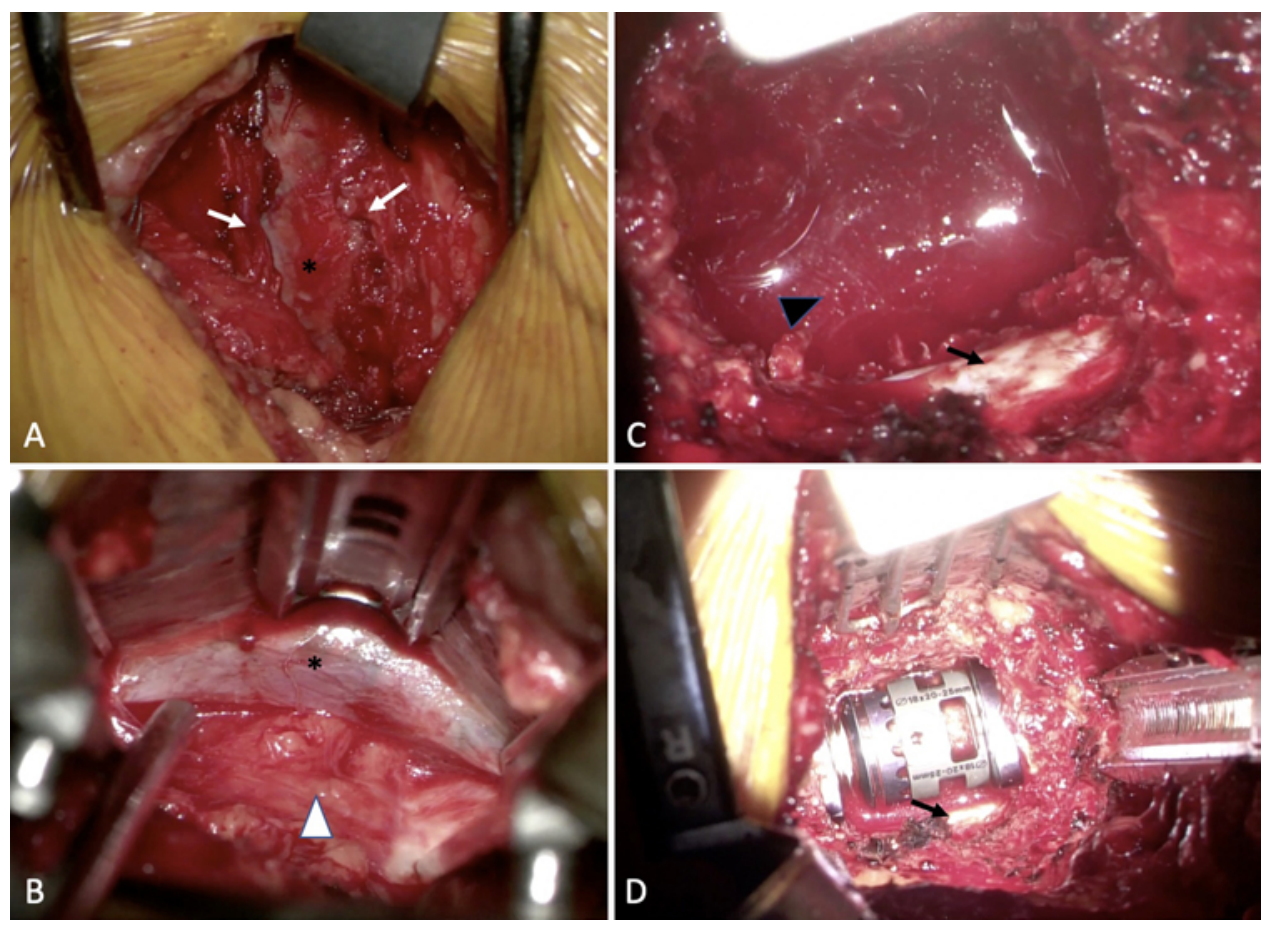

FIG. 1. Case 10. Intraoperative photographs. A: The retropleural space was developed between the endothoracic fascia (white arrows) and the parietal pleura $\left(^{*}\right)$ following removal of the rib. B: Further dissection detached parietal pleura $\left(^{*}\right)$ from lateral vertebra (white arrowhead). C: The corpectomy (black arrowhead) was performed to remove the hemangioma, and the posterior wall and epidural tumor were removed to decompress the thecal sac (black arrow). D: A rectangular expandable cage with autograft filled the corpectomy defect for anterior column support and arthrodesis.

and chronic fracture/deformity in 5 patients. Eight patients underwent single-level corpectomy and 3 had 2-level corpectomy. All patients had axial back pain with a mean preoperative VAS score of 8.2 (range 6-10). Six patients had neurological deficits as detailed in Table 1 . The average length of postoperative hospital stay was 7.2 days (range 2-19 days).

All patients had successful decompression and reconstruction. The mean postoperative VAS score improved to 2.2 (range 0-6). A chest tube was used in 1 patient with acute L1 fracture, despite the fact that there was no air leak, given a fair-sized parietal pleural breach that was not repaired and notable intraoperative bleeding at the corpectomy site. The chest tube was removed 2 days later. One patient with osteomyelitis developed increased leg weakness but subsequently improved to full strength at the most recent follow-up.

The preoperative kyphotic angle measured between the normal vertebra above and below the corpectomy site was $34.6^{\circ}$ (range $19.7^{\circ}-45.7^{\circ}$ ). The angle improved to $17.6^{\circ}$ (range $3.6^{\circ}$ lordosis to $30.2^{\circ}$ kyphosis) at 1 -month followup. This improvement persisted at the last follow-up with a mean of $19.7^{\circ}$ (range $3.7^{\circ}$ lordosis to $30.6^{\circ}$ kyphosis).

Early complications included 1 patient with deep venous thrombosis and pulmonary embolism and another with pneumonia. Both patients improved with medical treatment. The only patient with corpectomy supported by a stand-alone lateral plate developed recurrent back pain and cage subsidence 6 months postoperatively requiring posterior percutaneous pedicle screw fixation. She had resumed nicotine use against advice.

\section{Discussion \\ Surgical Routes for Anterior Thoracic and Thoracolumbar Lesions}

A few surgical routes are used to address anterior thoracic or thoracolumbar pathologies. Posterolateral approaches such as transpedicular, costotransversectomy, or lateral extracavitary procedures are familiar for most spine surgeons. Drawbacks are significant soft-tissue dissection and bony resection and the oblique view of the ventral thecal sac that limits the ability to maneuver for vertebral resection and correction of kyphotic deformity. To adequately address the anterior column lesions, especially those with large epidural components, open thoracotomy or a thoracoabdominal approach is usually performed to access the midthoracic to lower thoracic spine (T5-10) or thoracolumbar junction (T11-L1), respectively. Pulmonary complications associated with large open thoracotomy and diaphragm transgression can be significant, especially in patients with major trauma, systemic malignancy, and infectious process. ${ }^{1}$ The past decade has witnessed the advance of the minimally invasive approach with the goal of minimizing approach-related morbidities, reducing the amount of blood loss, decreasing postoperative pain, and facilitating early mobilization and discharge from the hospital. Data presented here demonstrate how a 
TABLE 1. Summary of patients undergoing lateral retropleural/retroperitoneal corpectomy

\begin{tabular}{|c|c|c|c|c|c|c|c|c|c|c|}
\hline $\begin{array}{l}\text { Case } \\
\text { No. }\end{array}$ & $\begin{array}{l}\text { Sexl } \\
\text { Age } \\
\text { (yrs) }\end{array}$ & Diagnosis & Corpectomy & Stabilization & $\begin{array}{l}\text { Preop } \\
\text { VAS } \\
\text { Score }\end{array}$ & Preop Deficits & $\begin{array}{l}\text { Postop } \\
\text { VAS } \\
\text { Score }\end{array}$ & $\begin{array}{l}\text { Hospital } \\
\text { Stay } \\
\text { (days) }\end{array}$ & $\begin{array}{l}\text { Follow-Up } \\
\text { (mos) }\end{array}$ & $\begin{array}{l}\text { Neurological } \\
\text { Outcome/ } \\
\text { Complication }\end{array}$ \\
\hline 1 & $\mathrm{~F} / 65$ & $\begin{array}{l}\text { Chronic fracture/ } \\
\text { deformity }\end{array}$ & $\mathrm{T} 12$ & $\begin{array}{l}\text { T9-ilium open } \\
\text { screws }\end{array}$ & 10 & None & 3 & 8 & 29 & \\
\hline 2 & $F / 36$ & $\begin{array}{l}\text { Chronic fracture/ } \\
\text { deformity }\end{array}$ & L1 & $\begin{array}{l}\text { T12-L2 lateral } \\
\text { plate }\end{array}$ & 9 & None & 6 & 6 & 17 & Cage subsidence \\
\hline 3 & $\mathrm{~F} / 44$ & $\begin{array}{c}\text { Breast cancer } \\
\text { metastasis }\end{array}$ & L1 & $\begin{array}{l}\text { T11-L3 perc } \\
\text { screws }\end{array}$ & 7 & $\begin{array}{l}\text { Hip flexion weak- } \\
\text { ness, thigh } \\
\text { numbness }\end{array}$ & 0 & 2 & 26 & Deficits resolved \\
\hline 4 & $\mathrm{M} / 17$ & Acute fracture & L1 & $\begin{array}{l}\text { T11-L3 perc } \\
\text { screws }\end{array}$ & 9 & $\begin{array}{l}\text { Hip flexion weak- } \\
\text { ness, thigh } \\
\text { numbness }\end{array}$ & 0 & 8 & 23 & Deficits resolved \\
\hline 5 & $\mathrm{M} / 79$ & Acute fracture & T9 & $\begin{array}{l}\text { T7-11 perc } \\
\text { screws }\end{array}$ & 6 & $\begin{array}{l}\text { Incontinence, leg } \\
\text { numbness }\end{array}$ & 1 & 7 & 14 & Deficits resolved \\
\hline 6 & $M / 52$ & Osteomyelitis & $\mathrm{T} 11,12$ & $\begin{array}{l}\text { T10-L2 perc } \\
\text { screws }\end{array}$ & 10 & None & 1 & 6 & 22 & \\
\hline 7 & $\mathrm{~F} / 74$ & $\begin{array}{l}\text { Chronic fracture/ } \\
\text { deformity }\end{array}$ & $\mathrm{T7}$ & $\begin{array}{c}\text { T5-9 perc } \\
\text { screws }\end{array}$ & 8 & None & 3 & 7 & 13 & \\
\hline 8 & $M / 62$ & Osteomyelitis & $\mathrm{T} 5,6$ & $\begin{array}{c}\text { T3-8 perc } \\
\text { screws }\end{array}$ & 8 & $\begin{array}{r}\text { Leg weakness, } \\
\text { sensory loss }\end{array}$ & 2 & 19 & 22 & $\begin{array}{l}\text { Temporarily wors- } \\
\text { ened weakness, } \\
\text { full strength at } \\
\text { last follow-up }\end{array}$ \\
\hline 9 & $M / 64$ & $\begin{array}{l}\text { Chronic fracture/ } \\
\text { deformity }\end{array}$ & $\mathrm{T7}$ & $\begin{array}{c}\text { T5-9 perc } \\
\text { screws }\end{array}$ & 8 & None & 3 & 4 & 6 & \\
\hline 10 & $M / 58$ & $\begin{array}{l}\text { Benign aggres- } \\
\text { sive heman- } \\
\text { gioma }\end{array}$ & T8 & $\begin{array}{l}\text { T6-10 perc } \\
\text { screws }\end{array}$ & 7 & $\begin{array}{l}\text { Unsteady gait, } \\
\text { sensation loss }\end{array}$ & 2 & 6 & 6 & $\begin{array}{l}\text { DVT/PE, sensa- } \\
\text { tion normal, gait } \\
\text { improved }\end{array}$ \\
\hline 11 & $\mathrm{~F} / 76$ & $\begin{array}{l}\text { Chronic fracture/ } \\
\text { deformity }\end{array}$ & $\mathrm{T} 10,11$ & $\begin{array}{l}\text { T7-L2 open } \\
\text { screws }\end{array}$ & 8 & $\begin{array}{l}\text { Leg weakness, } \\
\text { wheelchair } \\
\text { bound }\end{array}$ & 3 & 6 & 6 & $\begin{array}{l}\text { Pneumonia, } \\
\text { strength } \\
\text { improved, } \\
\text { remained wheel- } \\
\text { chair bound }\end{array}$ \\
\hline
\end{tabular}

DVT = deep venous thrombosis; $\mathrm{PE}=$ pulmonary embolism; perc = percutaneous.

mini-open lateral transthoracic retropleural or combined retropleural/retroperitoneal approach can address thoracic and thoracolumbar junction spinal pathologies with reasonable risks. Understanding the anatomy and several surgical nuances is key to success.

\section{Patient Positioning and Surgical Planning}

Lateral transthoracic retropleural approaches can be used for lesions between T5 and T10. The scapula and mediastinum structures will interfere with more cephalad approaches. Maintaining a true radiographic lateral position is critical for the mini-open lateral approach because this maneuver improves the surgeon's orientation. Because deformity and destructive lesions often obscure normal anatomical landmarks, true radiographic anterior-posterior and lateral intraoperative fluoroscopic images facilitate appropriate trajectories and reorientation as needed. Incision is based on the projected vertebral bodies of interest and the overlying rib is removed to gain access to the thoracic cavity. Usually the rib just cephalad to the targeted level is removed in upper and midthoracic levels and the rib 2 levels cephalad is removed at lower thoracic or thoracolumbar regions.

\section{Lateral Retropleural Dissection}

The key step after rib removal is to develop the retropleural space through meticulous dissection between the endothoracic fascia and parietal pleura. Sharp dissection is required initially to dissect adhesions that are more prevalent directly under surrounding ribs. This can then be followed with finger blunt dissection. Overzealous blunt dissection can lead to a large tear of pleura and should be avoided. The difficulty of this dissection can vary substantially and small tears are not uncommon. Widening the retropleural space craniocaudally first, using alternating sharp and blunt dissection, minimizes tension over the pleura before the dissection follows the curve of the chest wall dorsally and medially. When the pleura takes a sharp turn anteriorly over the lateral vertebral bodies, blunt dissection with a dilator or endo-Kittner minimizes potential 


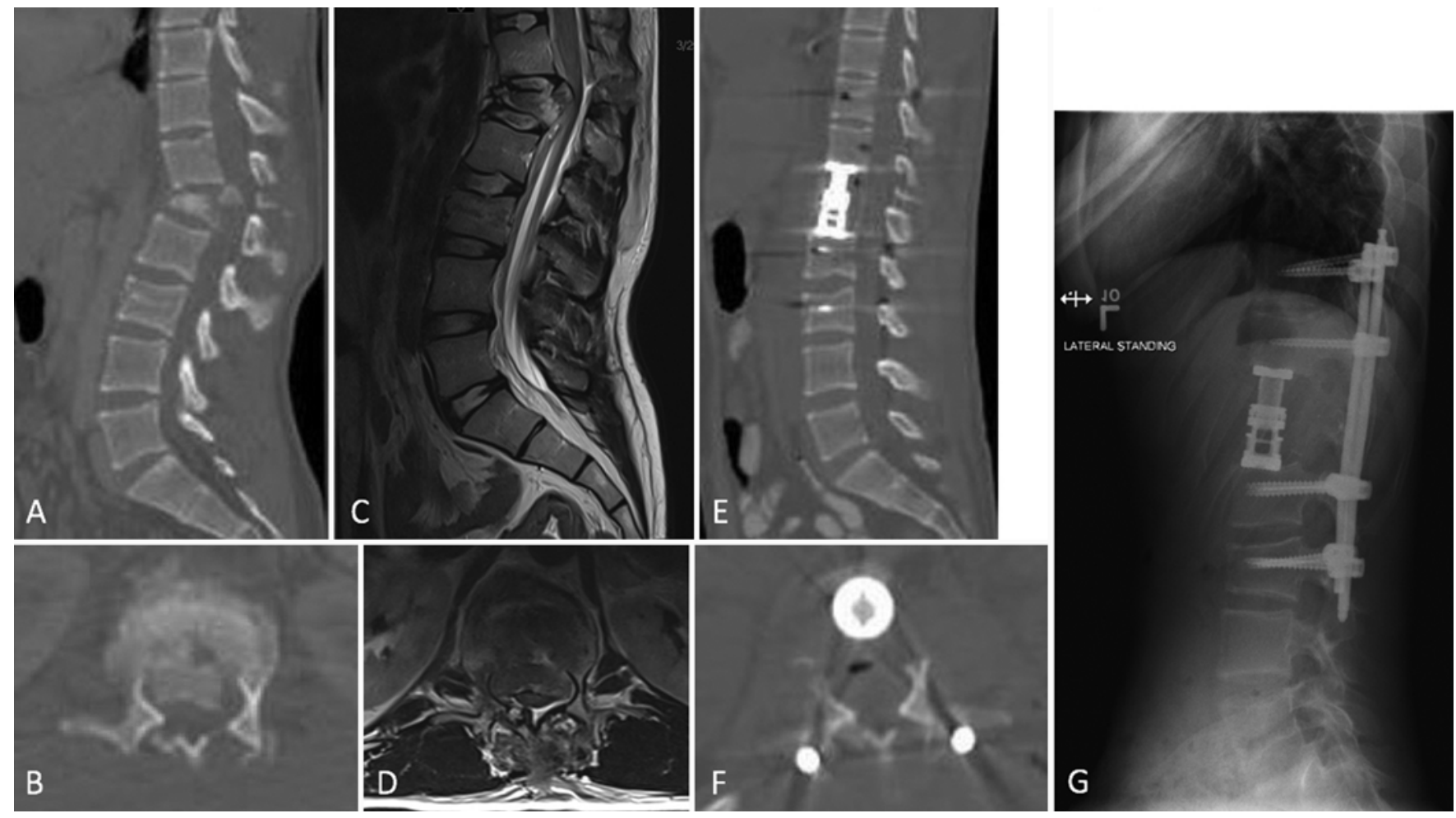

FIG. 2. Case 4. A 17-year-old male involved in a motor vehicle accident with L1 burst fracture causing focal kyphosis and severe spinal canal compromise as demonstrated on CT (A and B) and T2-weighted MRI (C and D). Postoperative CT images (E and F) obtained following a lateral retropleural/retroperitoneal L1 corpectomy show removal of the retropulsed fractured fragments and restoration of the anterior column. Posterior percutaneous pedicle screw fixation from T11 to L3 was performed to provide stability (G).
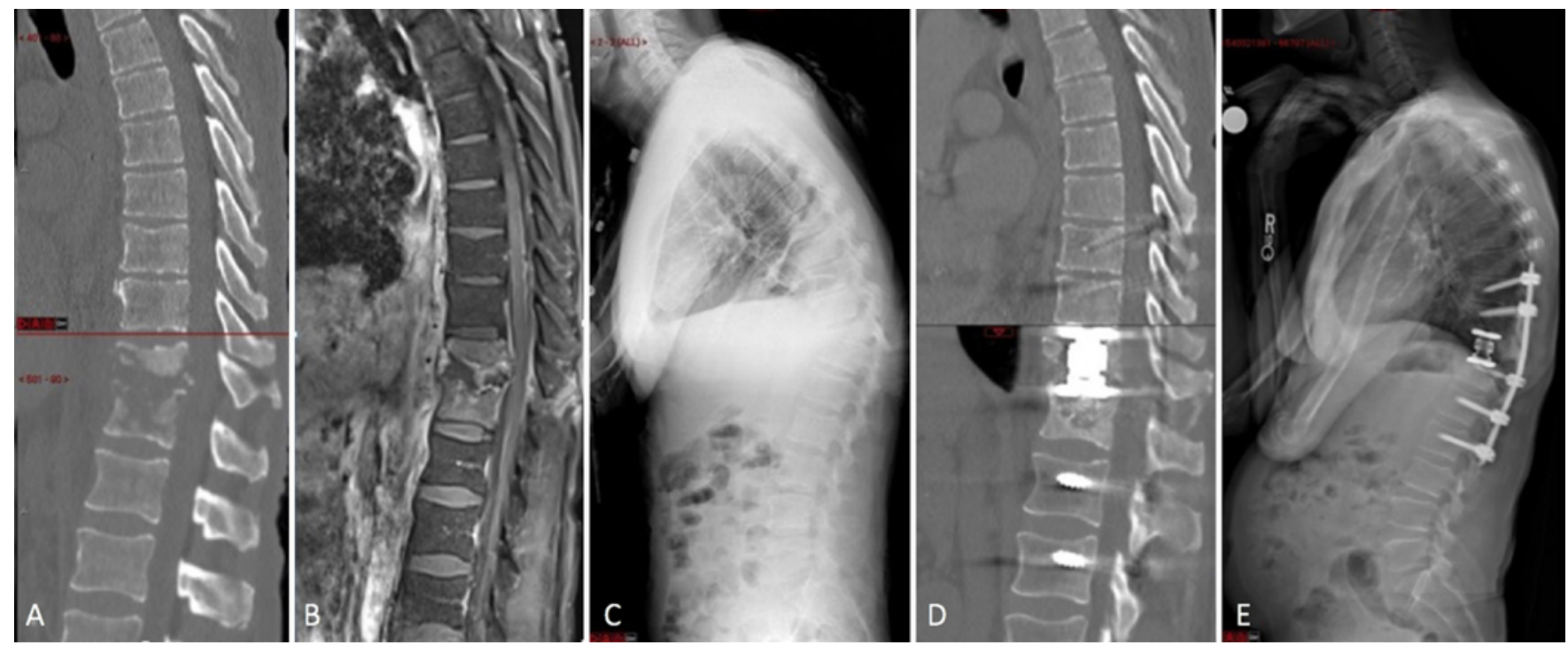

FIG. 3. Case 6. Sagittal CT (A) and T1-weighted contrast MRI (B) of a 52-year-old man demonstrating T11/12 osteomyelitis and discitis. Standing lateral radiograph $(\mathbf{C})$ revealing severe focal kyphosis. A lateral retropleural approach was carried out to remove the T11 vertebra and debride the upper part of the T12 vertebra. The T12 bony defect was filled with autograft and a rectangular expandable cage was placed in the corpectomy defect to correct the kyphosis (D). Postoperative radiograph (E) showing the spine construct, which was further supported with posterior T9-L2 percutaneous pedicle screw fixation. 
injury to the major vessels while exposing the vertebral bodies as far anterior as possible (Video 1).

VIDEO 1. Intraoperative video demonstrating a mini-open retropleural approach to perform a T8 corpectomy and removal of an aggressive vertebral hemangioma. Copyright Chun-Po Yen. Published with permission. Click here to view.

\section{Lateral Combined Retropleural/Retroperitoneal Approach}

The thoracolumbar junctional region is prone to spinal fractures and deformity, because it constitutes a transitional zone between the rigid thoracic spine and the relatively mobile lumbar spine. Anterior column access at the thoracolumbar junction is challenging due to the diaphragm. ${ }^{5}$ Understanding the diaphragm's lateral costal and posterior spinal attachments is of paramount importance in approaching the thoracolumbar junction. Laterally, the diaphragm attaches to the 9th-12th ribs (Fig. 4 upper). Posteriorly, the diaphragm attaches to the distal portion of the 12th rib via the lateral arcuate ligament, which arches over the quadratus lumborum muscle to attach to the ventral aspect of the L1 transverse process. It continues on as the medial arcuate ligament, arching over the psoas to the ipsilateral crus of the diaphragm on the anterolateral wall of L2 (left) or L3 (right) (Fig. 4 lower).

Traditional open thoracolumbar approaches entail entering the pleural cavity, cutting the diaphragm a few millimeters away from its insertions, and mobilizing peritoneum to expose the spinal column. With minimally invasive approaches, smaller retropleural and retroperitoneal dissections are needed before release of the diaphragm. For higher thoracolumbar junction lesions the retropleural space can be exposed, followed by release of the diaphragm to connect to the retroperitoneal space. ${ }^{3,6}$ For lower thoracolumbar lesions the retroperitoneum can be entered first, then communicate with the retropleural space after mobilizing the diaphragm., $3,7,8$

The "caudal to rostral" approach enters the retroperitoneal space first and the insertion of diaphragm to the abdominal wall is carefully incised ${ }^{8}$ or the medial arcuate ligament is retracted to connect the retroperitoneal space to retropleural space., ${ }^{3,7}$ The "rostral to caudal" approach enters the retropleural space first and detaches the diaphragm's costal and spinal attachments to enter the retroperitoneal space. With this approach, parts of the parietal pleura and diaphragm are detached from the chest/ abdominal wall when the T11 rib is removed. Caudally disconnecting the diaphragm from the T12 rib would lead to the retroperitoneal space. Wide exposure of anterolateral aspects of the thoracolumbar junction will require detachment of the lateral and subsequently medial arcuate ligament. Given that the diaphragm is intact and only a small portion of its insertion is detached, reestablishment of the diaphragm insertion is not required, and we have not observed adverse effects associated this maneuver., ${ }^{2,5}$

\section{Rib Head Removal}

Once the parietal pleura and diaphragm's insertions are detached, the residual endothoracic fascia and periosteum are cleaned off of the vertebral bodies and rib heads. The rib head articulates with the superior border of the corresponding vertebral body and inferior border of the
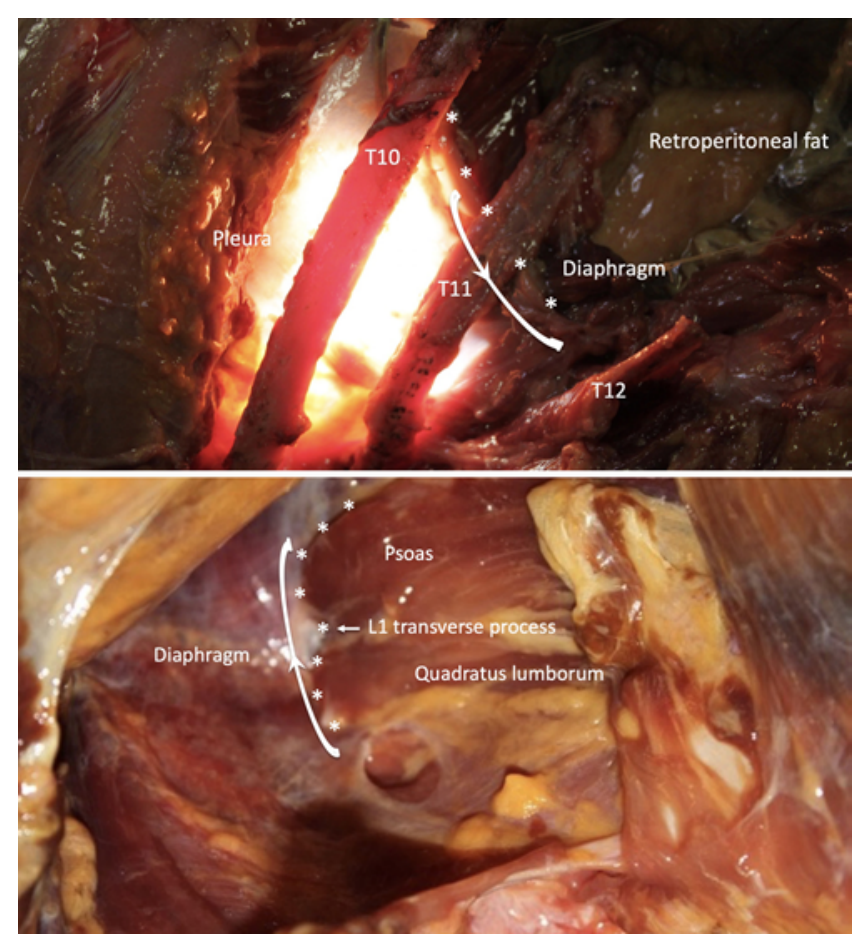

FIG. 4. Cadaveric dissection showing the diaphragmatic lateral and posterior attachments. Upper: The cadaver was placed in a lateral position with the pleural cavity illuminated. Removing the 11th rib will expose the junction of pleura and diaphragm and further posterior dissection of the diaphragm from the 12 th rib will reach the lateral attachment of the lateral arcuate ligament. Lower: View of diaphragm toward the dome and posterior attachment demonstrating the lateral and medial arcuate ligaments overarching quadratus lumborum and psoas muscles, respectively. Detaching the ligaments will expose the lateral aspects of the vertebral bodies.

cephalad vertebral body straddling the posterolateral disc space. The rib head of the uppermost level of corpectomy will need to be entirely removed. The rib head of the level below the caudal corpectomy needs to be removed at least partially to expose the disc below the corpectomy site. The exceptions are T11 and T12, where the corresponding rib heads only articulate with T11 and T12 vertebral bodies and the T10/11 and T11/12 disc spaces are accessible without removing the rib heads ${ }^{9}$ (Fig. 5).

\section{Corpectomy and Reconstruction}

Once the discs are exposed, the cartilaginous endplate can be detached from the bony endplate to mark the most rostral and caudal extent of corpectomy. At this point, corpectomy can be performed with drill, osteotome, or ultrasonic bone scalpel combined with rongeurs and pituitary forceps. True anterior-posterior radiographic images can help guide the depth of corpectomy. Depending on the goal of the surgery, the anterior wall can be left or removed in a piecemeal or en bloc fashion..$^{2,10}$ Once the corpectomy trough is created, pedicle resection exposes the anterolateral aspect of the thecal sac to guide the posterior extent of corpectomy. The posterior wall along with the epidural lesions (e.g., tumor, granulation tissue, and fracture frag- 


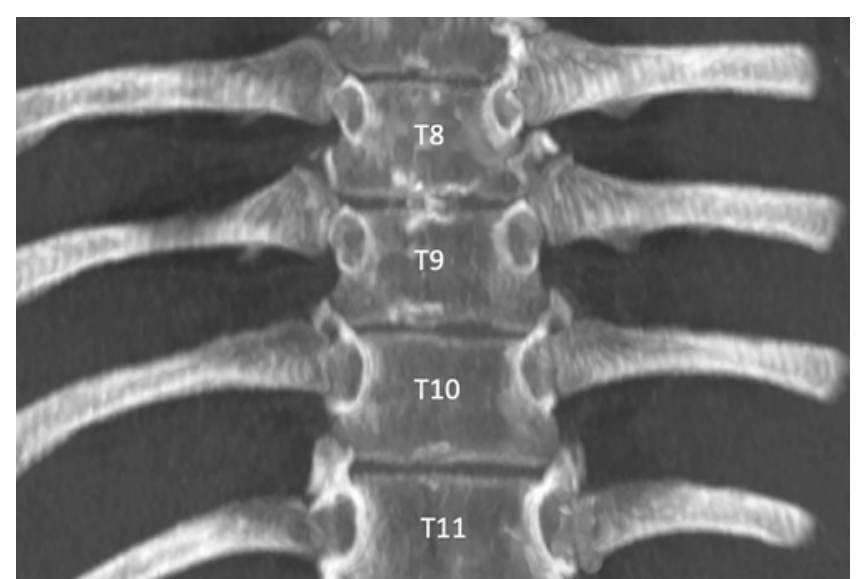

FIG. 5. Reconstructed 3D CT image demonstrating variations of costovertebral joints. Rib heads above T9 articulate with the corresponding vertebra and its caudal vertebra, thus covering the posterior aspect of the disc space. Rib heads below T10 only articulate with the posterosuperior corner of the corresponding vertebra.

ments) can be debulked and pushed away from the dura mater into the space provided from the corpectomy. The plane between posterior longitudinal ligament and dura is usually preserved and the residual lesions along with posterior longitudinal ligament can be dissected away from the thecal sac and removed.

An adequate lateral approach allows the placement of wide-footprint rectangular expandable cages spanning the hard cortical bone edges of the adjacent vertebral bodies, and may help decrease subsidence. Craniocaudal cage expansion will correct kyphotic deformity and restore sagittal alignment. Overzealous distraction of the expandable cage should be avoided to minimize destabilization of posterior column and potential cage subsidence. Stabilization of the anterior construct can be performed by means of anterolateral plating or posterior percutaneous pedicle screw fixation placed as a second stage. The posterior instrumentation minimizes the lateral exposure and provides stronger biomechanical stability but requires separate incisions.

\section{Advantages of Minimally Invasive Lateral Approach}

Lateral retropleural/retroperitoneal approaches provide several advantages. The approaches offer a direct route to the thoracic vertebra or thoracolumbar junction. A simultaneous view of vertebral pathologies and the thecal sac exposes anterior column pathologies without spinal cord manipulation, thus reducing the risk of neurological complications. Ipsilateral segmental vessels are readily identifiable and can be coagulated and divided. Contralateral segmental vessels can be visualized after the contralateral vertebral wall is removed and ligated. Wide-footprint rectangular expandable vertebral body replacement devices can be used to provide anterior column reconstruction and support. One-lung intubation and ventilation are not required. By keeping the pleura intact, there is lower risk of pulmonary complication and less risk of a duropleural CSF fistula if the dura is violated. The diaphragm is left intact and repair is not required. As with other minimally invasive approaches, less tissue disruption and limited rib resection afford less blood loss, reduced postsurgical pain, and shortened hospital stay.

\section{Limitation of Minimally Invasive Lateral Approach}

Retropleural dissection is challenging if not impossible in patients with prior thoracic surgery or infection causing significant adhesions between the endothoracic fascia and pleura. A small surgical corridor usually limits this approach to a short (1- to 2-segment) corpectomy and reconstructions. Long ( 3 or more segments) lesions can be managed with a similar approach, but a longer incision, resection of an extra rib, and further dissection might be needed to accommodate long-segment corpectomy and instrumentation. ${ }^{11}$

\section{Limitations of the Current Study}

The limitations of our study are a small cohort of patients and the lack of a comparison group. However, the purpose of the paper is to demonstrate the safety and efficacy of this approach for providing adequate exposure in treating patients with a variety of anterior column lesions of the thoracic region or thoracolumbar junction. We also recognize that the relatively short follow-up time in some of the patients is a weakness when assessing longterm outcome. Only one stand-alone lateral plate was used without posterior instrumentation. The resulting subsidence biased us against further use, so additional cases are not available to compare outcomes.

\section{Conclusions}

Mini-open lateral retropleural/retroperitoneal approaches provide an efficacious and safe option to achieve a corpectomy, anterior column reconstruction, and spinal deformity correction in patients with anterior thoracic or thoracolumbar pathologies. Compared to conventional open approaches, patients undergoing the mini-open lateral approaches have acceptable outcomes with potentially lower complication rates. A larger series and long followup and prospective comparative study are required.

\section{References}

1. McDonnell MF, Glassman SD, Dimar JR II, et al. Perioperative complications of anterior procedures on the spine. $J$ Bone Joint Surg Am. 1996;78(6):839-847.

2. Huangxs S, Christiansen PA, Tan H, et al. Mini-open lateral corpectomy for thoracolumbar junction lesions. Oper Neurosurg (Hagerstown). 2020;18(6):640-647.

3. Scheufler KM. Technique and clinical results of minimally invasive reconstruction and stabilization of the thoracic and thoracolumbar spine with expandable cages and ventrolateral plate fixation. Neurosurgery. 2007;61(4):798-809.

4. Smith WD, Dakwar E, Le TV, et al. Minimally invasive surgery for traumatic spinal pathologies: a mini-open, lateral approach in the thoracic and lumbar spine. Spine (Phila Pa 1976). 2010;35(26)(suppl):S338-S346.

5. Dakwar E, Ahmadian A, Uribe JS. The anatomical relationship of the diaphragm to the thoracolumbar junction during the minimally invasive lateral extracoelomic (retropleural/ retroperitoneal) approach. J Neurosurg Spine. 2012;16(4): 359-364.

6. Moskovich R, Benson D, Zhang ZH, Kabins M. Extracoelo- 
mic approach to the spine. J Bone Joint Surg Br. 1993;75(6): 886-893.

7. El Saghir H. Extracoelomic mini approach for anterior reconstructive surgery of the thoracolumbar area. Neurosurgery. 2002;51(5)(suppl):S118-S122.

8. Kim M, Nolan P, Finkelstein JA. Evaluation of 11th rib extrapleural-retroperitoneal approach to the thoracolumbar junction. Technical note. J Neurosurg. 2000;93(1)(suppl):168-174.

9. Moro T, Kikuchi S, Konno S. Necessity of rib head resection for anterior discectomy in the thoracic spine. Spine (Phila Pa 1976). 2004;29(15):1703-1705.

10. Turner JD, Zaidi HA, Godzik J, et al. Mini-open lateral en bloc corpectomy: cadaveric feasibility and early clinical experience. Clin Spine Surg. 2019;32(4):143-149.

11. Noureldine MHA, Pressman E, Krafft PR, et al. Minimally invasive lateral retropleural and retroperitoneal approaches in patients with thoracic and lumbar osteomyelitis: description of the techniques and a series of 14 patients. World Neurosurg. 2020;139:e166-e181.

\section{Disclosures}

Dr. Smith reports the following: 1) royalties from Zimmer Biomet, NuVasive, and Thieme; 2) consultant for Zimmer Biomet, Cerapedics, NuVasive, Stryker, DePuy Synthes, and Carlsmed; 3) direct stock ownership in Alphatec; 4) support of non-study-related clinical or research efforts overseen by the author from DePuy Synthes, ISSG, AO Spine, and NuVasive; 5) fellowship support from NREF and AO Spine; 6) membership on the editorial boards of Neurosurgery, Operative Neurosurgery, and Journal of Neurosurgery: Spine; and 7) membership on the board of directors of the Scoliosis Research Society. Dr. Uribe is a consultant for NuVasive, SI-BONE, and Misonix, and also receives royalties from and has direct stock ownership in NuVasive. Dr. Yen is a consultant for NuVasive.

\section{Author Contributions}

Conception and design: Yen, Christiansen, Huang, Uribe. Acquisition of data: Yen, Christiansen, Huang. Analysis and interpretation of data: Yen, Christiansen. Drafting the article: Yen, Christiansen, Huang. Critically revising the article: Yen, Christiansen, Smith, Uribe. Reviewed submitted version of manuscript: all authors. Approved the final version of the manuscript on behalf of all authors: Yen. Study supervision: Smith, Shaffrey, Uribe.

\section{Supplemental Information \\ Videos \\ Video 1. https://vimeo.com/439342942.}

\section{Correspondence}

Chun-Po Yen: University of Virginia Health System, Charlottesville, VA. chunpoyen@virginia.edu. 